\title{
Volume-controlled ventilation with superimposed high frequency ventilation during expiration in healthy and surfactant-depleted pig lungs
}

\author{
B. Lachmann, W. Schairer, M. Hafner, S. Armbruster and B. Jonson' \\ Department of Anesthesiology, Erasmus University, Rotterdam, The Netherlands and 'Department of Clinical Physiology, University of \\ Lund, Sweden
}

\begin{abstract}
In the healthy and surfactant-depleted lungs of five pigs the influence of different forms of high frequency ventilation superimposed on conventional mechanical ventilation during the expiratory phase of the ventilatory cycle (SHFVE) on gas exchange and cardiocirculatory parameters was investigated. Subsequently the effects of end-expiratory flushing $(\mathbf{E F})$, i.e. cleaning the large airways and connecting tubes from the ventilator free from end-expiratory $\mathrm{CO}_{2}$, with a volume greater than the dead space of the large airways and connecting tubes was investigated. SHFVE and EF resulted in a significant improvement in $\mathrm{CO}_{2}$ elimination in both healthy and surfactant-depleted lungs. Furthermore, in stiff lungs, at a certain level of oxygenation and $\mathrm{CO}_{2}$ elimination, SHFVE produced the lowest peak and mean airway pressure without any additional depression of cardiocirculatory parameters.
\end{abstract}

Key words: Airway pressure; ARDS; cardiocirculatory parameters; end-expiratory flushing; gas exchange; pig; superimposed high frequency ventilation.

The aim of ventilatory therapy is to maintain adequate gas exchange with minimal cardiocirculatory depression and barotrauma of the lung.

The side effects of artificial ventilation are related to the intrapulmonary airway pressure, especially when there is unequal distribution of ventilation (1). To minimise changes in airway pressure, one should investigate methods of decreasing dead space. If one flushes $\mathrm{CO}_{2}$ out of the large airways and connecting tubes from the ventilator during the expiratory phase, it should be possible to reduce tidal volume during volume-controlled ventilation and so to lower peak airway pressure. Two possible methods of achieving this are: (1) the superimposition of high frequency ventilation during the expiratory phase of the ventilatory cycle (SHFVE) or (2) an end-expiratory flush (EF) $(2,3)$. During EF the large airways, and the connecting tubes from the ventilator, are flushed with a volume of fresh gas larger than the dead space of the large airways and connecting tubes. The flushing volume has to be delivered to the carina via a special tube and has to start when the expiratory flow is zero.

The aim of this study was to investigate in pigs the influence of different frequencies combined with different pulse volumes during SHFVE and of varying flush volumes during EF in healthy and surfactantdepleted lungs on blood gases, intrapulmonary airway pressure and cardiocirculatory parameters.

\section{MATERIAL AND METHODS}

Five pigs (weighing 20-25 kg) were anesthetized with pentobarbital $(600 \mathrm{mg})$, intubated with a $35 \mathrm{Fr}$. Mallinckrodt Hi-Lo Jet ${ }^{\mathrm{TM}}$ tube, paralysed with pancuronium bromide $(0.08 \mathrm{mg} / \mathrm{kg} / \mathrm{h})$ and ventilated with a Siemens Servo Ventilator $900 \mathrm{C}$ (Siemens-Elema, Sweden) with a frequency of 12 breaths $/ \mathrm{min}$ and $\mathrm{FrO}_{2}=\mathrm{I}$.

The minute volume was set to maintain the arterial $\mathrm{CO}_{2}$ tension between $35-40 \mathrm{mmHg}$ during preparation. The I:E ratio was set to $25 \%$ inspiratory time and $10 \%$ pause time.

Catheters were placed in the femoral artery and vein and a SwanGanz catheter was placed in the pulmonary artery via the femoral vein. Cardiovascular monitoring was done by means of a Marquette monitor system $7000^{\mathrm{TM}}$ (Marquette Electronics Inv. Milwaukee, Ws, USA) and printed directly with a Marquette monitor printer 7100 . Blood gases and $\mathrm{pH}$ were measured with the blood gas analyser (ABL 330, Radiometer, Copenhagen). Intrapulmonary airway pressure was measured with a tip catheter pressure transducer (PPG Hellige, The Netherlands) connected to the Marquette monitor. Superimposed high frequency ventilation during expiration (SHFVE) was performed with a High Frequency Unit 970 (SiemensElema, Solna, Sweden) connected to and triggered by a Servo Ventilator 900C (Siemens-Elema, Solna, Sweden) and applied through the high frequency channel of the Hi-Lo Jet ${ }^{\mathrm{TM}}$ tube.

In healthy animals the following ventilator settings were used: during conventional mechanical ventilation (CMV) with the Servo Ventilator $900 \mathrm{C}$, the tidal volume was set to $18 \mathrm{ml} / \mathrm{kg} \mathrm{BW}$ and the frequency was set to 12 and 5 breaths $/ \mathrm{min}$. The slow ventilatory rate was used to induce hypercapnia between 60 and $70 \mathrm{mmHg}$. During expiration frequencies of $2.5,5$ and $15 \mathrm{~Hz}$ with corresponding pulse volumes of 32,16 and $6 \mathrm{ml}$ were superimposed. At these settings the duty cycle was set to $20 \%$. In addition, the influence of the pulse duration of $80 \%$ was tested at frequencies of 5 and $15 \mathrm{~Hz}$ and a 
Table !

Arterial $\mathrm{Pco}_{2}$ and $\mathrm{Po}_{2}$, cardiac output $(\mathrm{CO})$, peak airway pressure (Paw peak), mean arterial pressure ( $\mathrm{P}$ art), mean pulmonary pressure (P pulm) and dynamic PEEP in healthy animals during conventional mechanical ventilation (CMV) $(\mathrm{F}=12)$ with end-expiratory flush and with superimposed high frequency ventilation at different frequencies $(\mathrm{Hz})$ and pulse volumes (P.V.). Figures are given as means \pm SD. Statistical analysis was performed with the Wilcoxon's signed ranking test.

\begin{tabular}{|c|c|c|c|c|c|c|}
\hline & $\begin{array}{l}\text { CMV } \\
F=12\end{array}$ & $\begin{array}{l}\text { Flush } \\
100 \mathrm{ml}\end{array}$ & $\begin{array}{l}\text { Flush } \\
200 \mathrm{ml}\end{array}$ & $\begin{array}{c}2.5 \mathrm{~Hz} \\
\text { P.V. } 32 \mathrm{ml}\end{array}$ & $\begin{array}{c}5 \mathrm{~Hz} \\
\text { P.V. } 16 \mathrm{ml}\end{array}$ & $\begin{array}{c}15 \mathrm{~Hz} \\
\text { P.V. } 6 \mathrm{ml}\end{array}$ \\
\hline $\mathrm{PaCO}_{2}(\mathrm{mmHg})$ & $41 \pm 4$ & $34 \pm 5^{*}$ & $36 \pm 4$ & $36 \pm 5$ & $35 \pm 5$ & $30 \pm 4 *$ \\
\hline $\mathrm{PaO}_{2}(\mathrm{mmHg})$ & $448 \pm 53$ & $472 \pm 34$ & $502 \pm 38$ & $493 \pm 23$ & $512 \pm 17$ & $481 \pm 31$ \\
\hline $\mathrm{CO}(1 / \mathrm{min})$ & $4.0 \pm 0.6$ & $3.8 \pm 0.7$ & $3.1 \pm 0.6$ & $4.2 \pm 0.8$ & $4.4 \pm 0.9$ & $4.9 \pm 0.7$ \\
\hline Paw peak $\left(\mathrm{cm} \mathrm{H}_{2} \mathrm{O}\right)$ & $17.5 \pm 2$ & $20 \pm 2$ & $23 \pm 2^{*}$ & $21 \pm 2$ & $20 \pm 3$ & $19 \pm 2$ \\
\hline $\mathrm{P}$ art. $(\mathrm{mmHg})$ & $106 \pm 12$ & $102 \pm 16$ & $97 \pm 19$ & $102 \pm 14$ & $101 \pm 15$ & $107 \pm 18$ \\
\hline $\mathrm{P}$ pulm. (mmHg) & $11 \pm 3$ & $13 \pm 3$ & $15 \pm 4$ & $13 \pm 4$ & $12 \pm 4$ & $12 \pm 3$ \\
\hline Dynamic PEEP $\left(\mathrm{cm} \mathrm{H}_{2} \mathrm{O}\right)$ & 0 & $2 \pm 1^{*}$ & $4.4 \pm 2^{*}$ & $2 \pm 1^{*}$ & $3 \pm 2 *$ & $3 \pm 2^{*}$ \\
\hline
\end{tabular}

* = significant differences $(\mathrm{p}<0,05)$ to $\mathrm{CMV}$.

Table 2

Arterial $\mathrm{Pco}_{2}$ and $\mathrm{Po}_{2}$, cardiac output $(\mathrm{CO})$, peak airway pressure (Paw peak), mean arterial pressure ( $\mathrm{P}$ art), mean pulmonary pressure ( $P$ pulm) and dynamic PEEP in healthy animals during conventional mechanical ventilation (CMV) $(F=5)$ endexpiratory flush (Flush) and superimposed with high frequency ventilation at different frequencies $(\mathrm{Hz})$ and pulse volumes (P.V.). Figures are given as means \pm SD. Statistical analysis was performed with the Wilcoxon's signed ranking test.

\begin{tabular}{|c|c|c|c|c|c|c|}
\hline & $\begin{array}{l}\text { CMV } \\
F=5\end{array}$ & $\begin{array}{l}\text { Flush } \\
100 \mathrm{ml}\end{array}$ & $\begin{array}{l}\text { Flush } \\
200 \mathrm{ml}\end{array}$ & $\begin{array}{c}2.5 \mathrm{~Hz} \\
\text { P.V. } 32 \mathrm{ml}\end{array}$ & $\begin{array}{l}5 \mathrm{~Hz} \\
\text { P.V. } 16 \mathrm{ml}\end{array}$ & $\begin{array}{c}15 \mathrm{~Hz} \\
\text { P.V. } 6 \mathrm{ml}\end{array}$ \\
\hline $\mathrm{PacO}_{2}(\mathrm{mmHg})$ & $66 \pm 8$ & $52 \pm B$ & $56 \pm 9$ & $51 \pm 9$ & $47 \pm 8^{*}$ & $42 \pm 6^{*}$ \\
\hline $\mathrm{PaO}_{2}(\mathrm{mmHg})$ & $324 \pm 78$ & $355 \pm 48$ & $347 \pm 37$ & $338 \pm 73$ & $409 \pm 53$ & $446 \pm 42$ \\
\hline $\mathrm{CO}(1 / \mathrm{min})$ & $3.4 \pm 1.2$ & $3.6 \pm 0.9$ & $3.0 \pm 1.1$ & $3.9 \pm 1.3$ & $4.2 \pm 1.0$ & $4.8 \pm 0.8$ \\
\hline Paw peak $\left(\mathrm{cm} \mathrm{H}_{2} \mathrm{O}\right)$ & $19.3 \pm 2$ & $22 \pm 2$ & $25 \pm 3^{*}$ & $23 \pm 3$ & $22 \pm 2$ & $21 \pm 2$ \\
\hline $\mathrm{P}$ art. $(\mathrm{mmHg})$ & $95 \pm 14$ & $92 \pm 11$ & $88 \pm 12$ & $94 \pm 17$ & $96 \pm 16$ & $97 \pm 19$ \\
\hline $\mathrm{P}$ pulm. (mmHg) & $14 \pm 3$ & $15 \pm 4$ & $16 \pm 3$ & $14 \pm 3$ & $14 \pm 3$ & $12 \pm 4$ \\
\hline Dynamic PEEP $\left(\mathrm{cm} \mathrm{H}_{2} \mathrm{O}\right)$ & 0 & $2 \pm 1^{*}$ & $5 \pm 2 *$ & $1 \pm 1^{*}$ & $1 \pm 1^{*}$ & $2 \pm 1^{*}$ \\
\hline
\end{tabular}

* = significant differences $(\mathrm{p}<0.05)$ to $\mathrm{CMV}$.

frequency of 12 during CMV. Finally, the effects of an end-expiratory flush with volumes of 100 and $200 \mathrm{ml}$ were tested.

These different ventilation settings were applied in a randomized order to each animal and repeated three times. Then the animals' lungs were lavaged with warm saline $(1,4,5)$ to produce severe respiratory insufficiency resulting in an arterial $\mathrm{PaO}_{2}$ between 50 and

Table 3

Arterial $\mathrm{PCO}_{2}$ and $\mathrm{PO}_{2}$, cardiac output $(\mathrm{CO})$, peak airway pressure ( $P$ aw peak), mean arterial pressure $(P$ art $)$, mean pulmonary pressure (P pulm) and dynamic PEEP in healthy animals during conventional mechanical ventilation (CMV) $(\mathbf{F}=12)$ superimposed high frequency ventilation at different frequencies $(5$ and $15 \mathrm{~Hz})$ and duty cycles of $20 \%$ and $80 \%$. Figures are given as means \pm SD. Statistical analysis was performed with the Wilcoxon's signed ranking test.

\begin{tabular}{|c|c|c|c|c|}
\hline & $\begin{array}{l}5 \mathrm{~Hz} \\
20 \%\end{array}$ & $\begin{array}{l}5 \mathrm{~Hz} \\
80 \% \\
\end{array}$ & $\begin{array}{c}15 \mathrm{~Hz} \\
20 \%\end{array}$ & $\begin{array}{c}15 \mathrm{~Hz} \\
80 \%\end{array}$ \\
\hline $\mathrm{PaCO}_{2}(\mathrm{mmHg})$ & $35 \pm 5$ & $35 \pm 4$ & $30 \pm 4$ & $33 \pm 3$ \\
\hline $\mathrm{PaO}_{2}(\mathrm{mmHg})$ & $512 \pm 17$ & $480 \pm 28$ & $480 \pm 31$ & $480 \pm 46$ \\
\hline $\mathrm{CO}(1 / \mathrm{min})$ & $4.4 \pm 0.9$ & $4.7 \pm 0.8$ & $4.9 \pm 0.7$ & $4.5 \pm 1.1$ \\
\hline Paw peak $\left(\mathrm{cm} \mathrm{H}_{2} \mathrm{O}\right)$ & $20 \pm 3$ & $22 \pm 2$ & $19 \pm 2$ & $20 \pm 2$ \\
\hline $\mathrm{P}$ art. $(\mathrm{mmHg})$ & $101 \pm 15$ & $90 \pm 19$ & $107 \pm 18$ & $106 \pm 19$ \\
\hline $\mathrm{P}$ pulm. (mmHg) & $12 \pm 4$ & $13 \pm 3$ & $12 \pm 3$ & $12 \pm 2$ \\
\hline Dynamic PEEP & & & & \\
\hline$\left(\mathrm{cm} \mathrm{H} \mathrm{H}_{2} \mathrm{O}\right)$ & $3 \pm 2$ & $2 \pm 1$ & $3 \pm 2$ & $2 \pm 1$ \\
\hline
\end{tabular}

$70 \mathrm{mmHg}$ at ventilator settings of: frequency $12 ; \mathrm{Vt}=35 \mathrm{ml} / \mathrm{kg} ; \mathrm{I}: \mathrm{E}$ ratio of 1:2; static PEEP of $4 \mathrm{~cm} \mathrm{H}_{2} \mathrm{O}$.

After surfactant depletion we applied to the animals SHFVE (15 $\mathrm{Hz}$, duty cycle $20 \%$, pulse volume $6 \mathrm{ml}$ ) and $\mathrm{EF}$ of 100 and $200 \mathrm{ml}$ and static PEEP was set to $8 \mathrm{~cm} \mathrm{H}_{2} \mathrm{O}$ to prevent severe hypoxemia.

\section{RESULTS}

SHFVE at $15 \mathrm{~Hz}$ and $\mathrm{EF}\left(100 \mathrm{ml}\right.$ ) improved $\mathrm{CO}_{2}$ elimination during conventional mechanical ventilation in animals with healthy lungs without significantly influencing the cardiocirculatory parameters (Tables 1 and 2). $\mathrm{CO}_{2}$ elimination was also increased by SHFVE at 5 and $15 \mathrm{~Hz}$ when the initial $\mathrm{PCO}_{2}$ was above $60 \mathrm{mmHg}$. The duration of the duty cycle did not affect $\mathrm{CO}_{2}$ elimination or oxygenation at 5 or 15 $\mathrm{Hz}$ (Table 3).

In animals with surfactant-depleted stiff lungs SHF$\mathrm{VE}$ and $\mathrm{EF}$ also significantly improved $\mathrm{CO}_{2}$ elimination without additional depression of cardiocirculatory parameters (Table 4).

\section{DISGUSSION}

Superimposed HFV is reported to improve gas exchange under special circumstances (e.g. ARDS) in 
Table 4

Arterial $\mathrm{PCO}_{2}$ and $\mathrm{Po}_{2}$, cardiac output $(\mathrm{CO})$, peak airway pressure (Paw peak), mean arterial pressure ( $\mathbf{P}$ art), mean pulmonary pressure (P pulm) and dynamic PEEP in surfactant depleted animals during conventional mechanical ventilation (CMV) with a PEEP of 4 and $8 \mathrm{~cm} \mathrm{H}_{2} \mathrm{O}$ and $\mathrm{CMV}$ with a PEEP of $8 \mathrm{~cm} \mathrm{H}_{2} \mathrm{O}$ with endexpiratory flush (Flush) and with superimposed high frequency ventilation at a frequency of $15 \mathrm{~Hz}$, pulse volume (P.V.) of $6 \mathrm{ml}$. Figures are given as means $\pm S D$, Statistical analysis was performed with the Wilcoxon's signed ranking test.

\begin{tabular}{lccccc}
\hline & $\begin{array}{c}\text { CMV } \\
\text { PEEP }=4\end{array}$ & $\begin{array}{c}\text { CMV } \\
\text { PEEP }=8\end{array}$ & $\begin{array}{c}\text { Flush } \\
100 \mathrm{ml}\end{array}$ & $\begin{array}{c}\text { Flush } \\
200 \mathrm{ml}\end{array}$ & $\begin{array}{c}15 \mathrm{~Hz} \\
6 \mathrm{ml}\end{array}$ \\
\hline $\mathrm{PaCO}_{2}$ & & & & & \\
$\left(\mathrm{mmHg}^{2}\right)$ & $47 \pm 6$ & $43 \pm 4$ & $38 \pm 5$ & $35 \pm 4^{*}$ & $35 \pm 4^{*}$ \\
$\mathrm{PaO}_{2}$ & & & & & \\
$(\mathrm{mmHg})$ & $64 \pm 12$ & $248 \pm 72^{*}$ & $310 \pm 48^{*}$ & $328 \pm 32^{*}$ & $322 \pm 34^{*}$ \\
$\begin{array}{l}\mathrm{CO}(\mathrm{l} / \mathrm{min}) \\
\mathrm{Paw} \text { peak }\end{array}$ & $4.3 \pm 0.7$ & $3.6 \pm 0.9$ & $2.7 \pm 0.6^{*}$ & $2.4 \pm 0.5^{*}$ & $2.8 \pm 0.6^{*}$ \\
$\left(\mathrm{~cm} \mathrm{H} \mathrm{H}_{2} \mathrm{O}\right)$ & $29 \pm 3$ & $34 \pm 2^{*}$ & $37 \pm 4^{*}$ & $41 \pm 4^{*}$ & $30 \pm 2$ \\
$\mathrm{P}$ art. & & & & & \\
$(\mathrm{mmHg})$ & $102 \pm 9$ & $97 \pm 11$ & $101 \pm 8$ & $96 \pm 12$ & $98 \pm 9$ \\
$\mathrm{P}$ pulm. & & & & & \\
$(\mathrm{mmHg})$ & $19 \pm 4$ & $22 \pm 3$ & $15 \pm 4$ & $17 \pm 4$ & $16 \pm 3$ \\
$\begin{array}{l}\mathrm{Dynamic} \\
\mathrm{PEEP}\end{array}$ & & & & & \\
$\left(\mathrm{cm} \mathrm{H} \mathrm{H}_{2} \mathrm{O}\right)$ & - & - & $11 \pm 2$ & $15 \pm 2$ & $10 \pm 2$ \\
\hline
\end{tabular}

* = significant differences $(p<0.05)$ to CMV.

human beings (this volume). But from experimental results in pigs with acute respiratory failure we know that the reason for these findings may be the increased peak and mean airway pressures during SHFV. When the tidal volume and/or PEEP was increased during conventional volume-controlled ventilation to produce the same peak- or mean airway pressures as with superimposed HFV we failed to find any additional improvement in gas exchange with SHFV (unpublished observation). Thus the application of SHFV will not avoid the side effects of conventional volume controlled ventilation.

On the other hand, it appears that SHFVE and EF may help to remove $\mathrm{CO}_{2}$ from the large airways and the tube up to the $\mathrm{Y}$-piece, thus decreasing the volume of $\mathrm{CO}_{2}$ reinspired during the next inspiratory cycle. This may also explain why SHFVE and EF appear to be more effective when the initial arterial $\mathrm{PCO}_{2}$ is high. The better results with higher frequencies may also imply that there are some additional effects on $\mathrm{CO}_{2}$ elimination during HFV.

Although a given arterial $\mathrm{CO}_{2}$ tension may be maintained with a smaller tidal volume and peak pressure using either SHFVE or EF when they are added to conventional mechanical ventilation, these techniques proved inferior to pressure-controlled ventilation with a prolonged inspiratory cycle up to $80 \%$ (unpublished observation).

\section{REFERENCES}

1. Lachmann B, Danzmann E, Haendly B, Jonson B. Ventilator settings and gas exchange in respiratory distress syndrome. In: Prakash $\mathrm{O}$ ed. Applied physiology in clinical respiratory care. The Hague: Martinus Nijhoff Publishers, 1982: 141-176.

2. Wolff G, Regazzoni P, Schuppisser J, Langenstein H. A simple method to decrease dead space ventilation. Int Care Med 1980: 6: 67 .

3. Jonson B, Similowski T, Fleury B et al. Expiratory flushing of large airways. Am Rev Respir Dis 1987: 135: A55.

4. Lachmann B, Robertson B, Vogel J. In vivo lung lavage as an experimental model of the respiratory distress syndrome. Acta Anaesthesiol Scand 1980: 24: 231-236.

5. Lachmann B, Jonson B, Lindroth M, Robertson B. Modes of artificial ventilation in severe respiratory distress syndrome. Lung function and morphology studied in rabbits after washout of alveolar surfactant. Crit Care Med 1982: 10: 724-732.

Address:

Prof. Dr. B. Lachmann

Department of Anesthesiology (EE 2393)

Erasmus University

Postbox 1738

NL-3000 DR Rotterdam

The Netherlands 